\title{
MARKET FAILURES AND THE EVOLUTION OF STATE REGULATION OF MANAGED CARE
}

\author{
FRANK A. SLOAN* AND MARK A. HALL**
}

\section{INTRODUCTION}

States have enacted numerous statutes in response to widespread dissatisfaction with managed care, which was exacerbated by its growth during the 1990s. Known as managed care patient care laws, the statutes address concerns of consumers and medical care providers. Organized medicine, a very effective political force, harnessed consumer dissatisfaction. ${ }^{1}$ Accordingly, the first wave of laws, prior to the mid-1990s, was primarily the result of lobbying by physicians and focused on "any-willing-provider" laws and laws requiring the inclusion of certain types of providers (such as dermatologists, chiropractors, and acupuncturists) in managed care networks. ${ }^{2}$ Starting in 1995 and 1996, states began to enact laws to address consumer concerns. ${ }^{3}$

Hundreds of managed care laws have been enacted. Statutory changes were made to existing laws designed to address insurer insolvency ${ }^{4}$ and quality of care. ${ }^{5}$ The laws include (in various combinations): ${ }^{6}$ (1) liability and appeal

Copyright (C) 2002 by Frank A. Sloan and Mark A. Hall

This article is also available at http://www.law.duke.edu/journals/65LCPSloan.

* J. Alexander McMahon Professor of Health Policy, Law and Management, Professor of Economics, and Director of the Center for Health Policy, Law and Management, Duke University.

** Professor of Law and Public Health, Wake Forest University.

We are grateful for the support provided by a research grant from the Robert Wood Johnson Foundation, through its program on Changes in Health Care Financing and Organization, administered by the Academy for Health Services Research and Health Policy, and for the research assistance from Janice Lawlor, M.P.H. and Kelly Leerberg.

1. See Richard Sorian \& Judith Feder, Why We Need a Patient's Bill of Rights, 24 J. HeAlth Pol. POL'Y \& L. 1137, 1139 (1999).

2. Jill A. Marsteller et al., The Resurgence of Selective Contracting Restrictions, 22 J. HEALTH POL. POL'Y \& L. 1133, 1137 (1997).

3. Tracy E. Miller, Managed Care Regulations: In the Laboratory of the States, 278 JAMA 1102 (1997); Alice A. Noble \& Troyen A. Brennan, The Stages of Managed Care Regulation: Developing Better Rules, 24 J. HeAlth POL. POL'Y \& L. 1275, 1281-83 (1999); Sorian \& Feder, supra note 1, at 1140.

4. See Henry T. Greely, The Regulation of Private Health Insurance, in HEALTH CARE CORPORATE LAW: Formation AND REgulation (Mark A. Hall ed., 1999). (1998).

5. See Troyen A. Brennan, The Role of Regulation in Quality Improvement, 76 MILBANK Q. 709

6. For a description and categorization of these laws using a similar, but contrasting, scheme, see Jill A. Marsteller \& Randall R. BovbJerg, Urban Inst., Federalism and Patient 
provisions-the right to an external review of coverage denials and the right to bring a tort suit against a health plan; (2) provisions affecting choice of and access to providers, such as "any-willing-provider" laws, point-of-service options, and direct access to specialists; (3) protecting providers from undue influence, such as by limiting physician incentives, banning "gag clauses," and giving providers due process rights when they are terminated from a plan; and (4) provisions governing general coverage standards (medical necessity and emergency care) and specific coverage mandates, such as minimum maternity stays.

Sources of dissatisfaction with managed care are well-documented. Although most consumers are satisfied with their actual experiences with managed care plans, and the observable quality of care remains high, ${ }^{8}$ the public has a generalized concern that managed care plans will lower quality of care, in part by restricting access to beneficial care in an effort to save money for the plan. ${ }^{9} \quad$ Such restrictions are thought to take a variety of forms, including restrictions on access to emergency room care, to specialists, and to other costly care that may potentially be beneficial to the plan enrollee. To the extent that real savings are generated, many consumers and physicians believe that such savings accrue to equity holders of the plans' corporate sponsors rather than to reduced premiums for customers. ${ }^{10}$ Patients' reactions to managed care strategies, such as gatekeeping, preauthorization of referrals, and financial incentives for physicians depend in part on whether they are construed to improve quality of care (considered to be good) or to lower cost (considered to be bad). ${ }^{11} \quad$ Physicians complain that they face constraints on care decisions imposed by plans. ${ }^{12}$ As with consumers, however, the documented reality is not as bad for physicians as is often portrayed. ${ }^{13}$ Providers are also concerned about

Protection: Changing Roles for State And Federal Government (1999), available at http://newfederalism.urban.org/pdf/occa28.pdf (last visited Sept. 19, 2002).

7. See Brennan, supra note 5.

8. See Joseph D. Gottfried \& Frank A. Sloan, The Quality of Managed Care: Evidence from the Medical Literature, 65 LAW \& CONTEMP. PROBS. 103 (Autumn 2002).

9. Robert J. Blendon et al., Understanding the Managed Care Backlash, HEALTH AFF., Jul./Aug. 1998, at 80, 84; Stephen M. Davidson, Can Public Policy Fix What Ails Managed Care?, 24 J. HEALTH POL. POL'Y \& L. 1051, 1052-53 (1999); Paul B. Ginsburg \& Cara S. Lesser, The View from Communities, 24 J. Health POL. POL'Y \& L. 1005, 1006 (1999); Gottfried \& Sloan, supra note 8, at 103-104.

10. See Blendon et al., supra note 9, at 87-88.

11. R. Adams Dudley \& Harold S. Luft, Managed Care in Transition, 344 NEw ENG. J. MED. 1087, 1089 (2001).

12. Karen Davis \& Cathy Schoen, Assuring Quality, Information, and Choice in Managed Care, 35 INQUIRY 104, 106 (1998).

13. See, e.g., Dahlia K. Remler et al., What Do Managed Care Plans Do to Effect Care? Results from a Survey of Physicians, 34 INQUIRY 196 (1997). A survey of 766 primary-care physicians practicing in California revealed that seventeen percent of physicians felt that pressure to limit the number of referrals they authorized was sufficiently severe to adversely affect the quality of care they could deliver. Ten percent said that the pressure to limit what they told patients about treatment options compromised quality of care. Kevin Grumbach et al., Primary Care Physicians' Experience of Financial Incentives in Managed Care Systems, 339 NEW ENG. J. MED. 1516, 1518 (1998). Although the same study revealed that physicians are dissatisfied with the pressure under managed care to see more 
the discounts that managed care plans are able to negotiate, but the vast majority of statutes address issues of access and quality of care rather than payment.

Defenders of managed care respond to these allegations in three ways: (1) they question the validity of the criticisms of managed care; (2) they observe that some of the allegations pertain to health insurance more generally and not just to managed care; and (3) they question whether the cure is more socially desirable than the alleged market failure itself. ${ }^{14}$

The general parameters of this debate are well-developed in the literature summarized above. What is less understood is the justification for managed care regulation in terms of well-articulated market failures (rather than simply political responses to public and interest group concerns); also needed is an examination of how well legal enactments and enforcement activities respond to market failure theory. ${ }^{15}$ Accordingly, this article addresses two issues. First, what is the conceptual basis for managed care patient protection laws? That is, what are the market failures that the laws specifically address or do not address? Is there a basis for concluding that managed care patient protection laws are welfare-enhancing in the sense that the potential failures of public regulation are minor relative to the failures of the managed care market? Second, this article presents results of a fifty-state survey of state managed care protection laws and their enforcement. This article does not assess the effects of such laws, but rather gauges whether the laws as enacted and implemented by the states, and proposed in Congress, have the potential to address the market failures identified in the previous section. Ultimately, this article

patients, patient visits, on average, are not getting shorter. David Mechanic, The Managed Care Backlash: Perceptions and Rhetoric in Health Care Policy and the Potential for Health Care Reform, 79 MilbanK Q. 35, 37-38 (2001).

To the extent that physicians anticipated denials of authorization, they may preemptively behave in the ways the plans desire them to behave. In this sense, data on actual denials may be misleading. For a summary of evidence on denial rates, see Mechanic, supra, at 45-46.

In August 1997, the U.S. General Accounting Office ("GAO") reported on a review of contracts from 529 HMOs. They found that none of the contracts had specific provisions expressly restricting physicians from discussing treatment options with their patients. Two-thirds of the contracts, however, had nondisparagement, nonsolicitation, or confidentiality clauses. GAO concluded that these types of clauses were not likely to affect a physician's decisions to discuss options with patients. U.S. GEN. Accounting OfFice, Managed CARe: Explicit Gag Clauses Not Found in HMO CONTRACTS, BUT PHYSICIAN CONCERNS REMAIN (1997).

14. See, e.g., David A. Hyman, Consumer Protection in a Managed Care World: Should Consumers Call 911?, 43 Vill. L. REV. 409, 453-58, $462-66$ (1998); David A. Hyman, Regulating Managed Care: What's Wrong with a Patient Bill of Rights, 73 S. CAL. L. REV. 221, 223, 234-37, 242-43, 254 (2000).

15. This is cogently observed in DEBORAH L. ROgal \& ROBERT J. STENGER, ACAD. FOR Health Services Research \& Health Policy, The Challenge of Managed Care REGULATION: MAKING MARKETS WORK? (2001), available at http://www.hcfo.net/ pdf/managedcare.pdf (last visited Sept. 19, 2002). For other articles that take a market theory perspective on this set of laws, see William Encinosa, The Economics of Regulatory Mandates on the HMO Market, 20 J. HEALTH ECON. 85 (2001); Russell Korobkin, The Efficiency of Managed Care "Patient Protection" Laws: Incomplete Contracts, Bounded Rationality, and Market Failure, 85 CORnell L. REV. 1 (1998); Mark Pauly \& Marc Berger, Why Should Managed Care be Regulated, in Regulating MANAGEd CARE: TheORY, Practice, AND Future Options (Stuart H. Altman et al. eds., 1999). 
concludes that, although there are some deficiencies in managed care markets as currently constituted, the patient protection laws overall do not address many of the most important deficiencies.

\section{II}

THE CONCEPTUAL CASE For AND AgAinst MANAGED CARE PATIENT PROTECTION LAWS

A. Consumer Ignorance and Asymmetric Information

\section{Critique}

Economists have drawn a useful distinction among search, experience, and credence goods. Search goods can be evaluated by consumers at a reasonable cost prior to purchase. ${ }^{16}$ Such goods either have physical properties that are easy to evaluate (for example, the cut of a shirt), or there is good information from readily available sources about the properties of the good. This may take the form of private information sources, such as Consumer Reports or Car and Driver, or simply from word of mouth. One can learn a lot about a good by asking friends and acquaintances for opinions. ${ }^{17}$ In some cases, a public agency such as the Food and Drug Administration requires disclosure of physical properties so that the product has acquired the characteristic of a search good, at least for some aspects, such as the number of calories and cholesterol content of specific food items. Otherwise, such information would be costly for the individual consumer of the product to monitor.

A second category is experience goods. Such goods must be consumed before consumers can assess their quality. For example, one may be able to know the calorie content of food from a label, but determining whether the food is tasty requires actual use. One might learn something about taste from a friend who has similar tastes, but the proof of the pudding is in the eating. In this sense, most foods are both search and experience goods. The costs of trying new experience goods are usually low. At most, if the good is not tasty, the consumer is out one or a few units. Other examples of experience goods are the medical services of one's primary care physician or the teaching of a professor. While the consumer may gain some information from the supplier's reputation, in the end, it is necessary for the consumer to try a unit to really gauge its quality accurately.

The third type of good is a credence good. ${ }^{18}$ For such goods, quality cannot be judged by the ordinary consumer even after the good is consumed. Given

16. Korobkin, supra note 15 , at $27-28$ (discussing search, experience, and credence goods in the context of managed care).

17. Mark A. Satterthwaite, Consumer Information, Equilibrium Industry Price, and the Number of Sellers, 10 BELL J. ECON. 483, 484, 494-98 (1979). (1997).

18. See generally Winand Emons, Credence Goods and Fraudulent Experts, 28 RAND J. ECON. 107 
such lack of information, it is up to the consumer to trust that the product or service is good, hence the term "credence." In the context of medical care, a patient will often be able to judge whether the outcome of care is favorable or unfavorable, but may not be able to determine whether the physician practiced good medicine or actually affected the outcome. Given the inability to gauge quality, care is "non-contractible" in the sense that the quality of care cannot be accurately determined at a reasonable cost, even ex post facto. ${ }^{19}$ For this reason, a profit-motivated seller may be tempted to skimp on resources since the buyer cannot really determine whether adequate resources were allocated to provision of the good. In such situations, there is a case for public provision, or at a minimum, the removal of the financial incentive to skimp on care. This case is weakened by the difficulty regulators also have in observing true quality, although regulators will most likely have better access to specialized monitors of quality than ordinary consumers.

Managed care may be a credence good in two senses. First, consumers have difficulty gauging the quality of medical care, especially types of medical care that are infrequently consumed, such as chemotherapy for breast cancer or coronary bypass surgery for ischemic heart disease..$^{20}$ Second, the complexity of the contract may make it very costly for the ordinary consumer to make comparisons among the few alternative plans most consumers have. Although consumers may be able to process information on a few characteristics, where there are too many characteristics it is too difficult for most consumers to process. For example, ex ante, a potential enrollee with a history of heart disease may be knowledgeable about the cardiologists in each of the managed care organization's ("MCOs") networks, which from the standpoint of the functioning of insurance markets is problematic in its own right. ${ }^{21}$ However, in a particular year, if the person develops a particular form of cancer, he may be locked into a provider network without good oncologists. Or the person may not have paid adequate attention to the coverage of cancer treatment ex ante and now must face the choice of either receiving lower quality care or paying for the better care out-of-pocket.

Because of the inherent complexity of plan choice, what might otherwise be a search good becomes a credence good. The consumer's problem is potentially

19. Oliver Hart \& Andrei Shleifer, The Proper Scope of Government: Theory and an Application to Prisons, 112 Q.J. ECON. 1127 (1997).

20. Mark V. Pauly, Is Medical Care Different?, in COMPETITION In the HeAlth CARE SeCtor: PAST, PRESENT, AND FUTURE 11, 12-13 (Warren Greenberg ed., 1978). There is a body of literature indicating that physicians themselves are often unable to make rational, evidence-based judgments about the appropriateness of particular services for particular patients. See, e.g., Donald W. Moran, Federal Regulation of Managed Care: An Impulse in Search of Theory, HEALTH AFF., Nov./Dec. 1997, at 7. This gives greater force to the consumer ignorance argument, but it limits the force of the information asymmetry argument.

21. This is a problem of adverse selection. People who anticipate substantial use of specialty care may select health plans with the best (and most costly) specialists in their networks. For general discussions of this phenomenon, see, for example, David M. Cutler \& Richard J. Zeckhauser, The Anatomy of Health Insurance, in HANDBOOK OF HEALTH ECONOMICS 606 (A. J. Culyer \& J. P. Newhouse eds., 2000) [hereinafter HANDBOOK]. 
exacerbated if the physician has a financial incentive to withhold care or if the physician is bound by the plan to withhold information about treatments that may be costly to the plan but potentially beneficial to the patient. The public seems distrustful of the motives of decision-makers who are accountable to private self-interest and stockholders. ${ }^{22}$ The traditional safeguard for the credence good problem has been physician professionalism, but this attitude has been eroding, ${ }^{23}$ and it serves as an imperfect consumer safeguard in its own right. ${ }^{24}$

The credence good issue is more significant under managed care than under traditional indemnity insurance for this reason: Under indemnity insurance, a person has a free choice of provider without financial consequences at the time of illness. Under managed care, the person agrees in advance to the plan, which has a contractual right to regulate medical care at the time illness occurs. The patient/consumer always has the option of paying for care denied by the plan out-of-pocket, but denial of coverage is often viewed by the public as "rationing," even though consumers in their role as employees should benefit from lower premiums. Thus, consumers need to be more forward-looking under managed care than under traditional indemnity insurance. ${ }^{25}$ Although the private managed care market has undertaken efforts to provide comparative information to consumers, overall, these efforts have not engendered much confidence that consumers are truly better informed about characteristics of alternative health plans. ${ }^{26}$ In recent years, direct access to specialists has

22. See Mark A. Hall, The Theory and Practice of Disclosing HMO Physician Incentives, 65 LAW \& CONTEMP. PROBS. 207, 208 (Autumn 2002); David Mechanic, Managed Care and the Imperative for a New Professional Ethic, HeALTH AFF., Sept/Oct. 2000, at 108.

23. Ezekiel J. Emanuel \& Lee Goldman, Protecting Patient Welfare in Managed Care: Six Safeguards, 23 J. HeAlth Pol. PoL'y \& L. 635 (1999); William M. Sage, Physicians as Advocates, 35 HOUS. L. REV. 1529, 1551-53, 1584-97 (1999).

24. James F. Blumstein \& Frank A. Sloan, Redefining Government's Role in Health Care: Is a Dose of Competition What the Doctor Should Order?, 34 VAND. L. REV. 849 (1981). Reliance on professional "norms" has at least two limitations in this context. First, physician and consumer preferences for care may not coincide. Second, physicians may pursue their own financial interests, which may lead to choices that are not in the patient's best interests.

25. For discussions of the incidence of health insurance premiums, see Alan B. Krueger \& Uwe E. Reinhardt, The Economics of Employer versus Individual Mandates, HEALTH AFF., Spring II 1994, at 34; Mark V. Pauly, HeAlth Benefits At Work: AN ECONOMiC AND Political ANAlysis OF EMPLOYMENT-BASED HeAlth InsuranCE (1997); Uwe E. Reinhardt, The Predictable Managed Care Kvetch on the Rocky Road from Adolescence to Adulthood, 24 J. HEALTH POL. POL'Y. \& L. 897, 90304 (1999).

26. See Moran, supra note 20, at 13 . In North Carolina (a relatively populous state) in 2002 , there were three Medicare health plans (health maintenance organizations) available to Medicare enrollees. The plans only covered selected locations within the state, and residents of particular locations had at most two choices. A brochure described the options, listing only the plan name, the plan service area, monthly premium, type of HMO, the copay amount, and whether prescription drug coverage, routine physical exams, and vision services were included. There are, of course, many other dimensions that consumers may find relevant to their choice of plan. See CTRS. FOR MEdiCARE \& MEdiCAID SERVS., MEDICARE \& YOU (2002), at http://www.medicare.gov/Publications/Pubs/pdf/mandy; Lauren D. Harris-Kojetin et al., Beneficiaries' Perceptions of New Medicare Health Plan Choice Print Materials, 23 HeAlTh CARE FinANCING REV. 21 (2001) (providing assessments of information provided to Medicare beneficiaries in general and of the MEDICARE \& YOU publication in particular); Lauren A. McCormack et al., Beneficiary Survey Based Feedback on New Medicare Informational Materials, 23 HEALTH CARE FINANCING REV. 37 (2001) (same). 
become a sought-after feature by consumers. ${ }^{27}$ The trend away from the gatekeeper model seems to indicate that patients either are not or do not want to be forward-looking.

In another sense, managed care bears a resemblance to an experience good as well. Normally, if one does not like a good, one can switch to the competitor's product. But in this context, the critics argue that this market-disciplining force is absent since (1) patients' options may be limited by employers' choices or by open enrollment restrictions; (2) the competing plans may have the same objectionable features, ${ }^{28}$ and (3) salient details that may account for a consumer's adverse experience are not disclosed. Lacking an exit voice, legislation is the main voice option. ${ }^{29}$

\section{Counterpoint}

The notion that consumers of medical care have imperfect information and physicians have better health information than their patients is neither new in general nor unique to managed care in particular. ${ }^{30}$ Likewise, the concept of limitations on individuals' cognitive ability to process large and complicated problems-bounded rationality-is about as old. ${ }^{31}$ The key to this debate is how one regards these limitations on perfect information and rationality. If one assumes that such limitations are minor, tolerable, or inevitable, then it is unnecessary to protect people against the consequences of their choices. However, if people are not considered to be informed, rational consumers, even under normal circumstances, this implies that there is a need for some form of public intervention to improve information flow.

At the most general level, arguments about consumer knowledge and rationality rapidly become unproductive. People may be forward-looking and reasonably informed about some decisions, such as the decision to seek an education in a profession, ${ }^{32}$ but myopic about others, such as an adolescent's decision to start smoking. ${ }^{33}$ Whether assumptions of adequate knowledge and

27. See Ginsburg \& Lesser, supra note 9, at 1010-11.

28. See Emanuel \& Goldman, supra note 23, at 641.

29. Marc A. Rodwin, Backlash as Prelude to Managing Care, 24 J. HeAlth POL. POL'Y \& L., 1115, 1119 (1999) [hereinafter Rodwin, Backlash]. For greater detail, see Marc A. Rodwin, Consumer Protection and Managed Care: Issues, Reform Proposal, and Trade-offs, 32 Hous. L. REV. 1321 (1996). In a medical care context in general, he argues that an individual consumer is rarely in a favorable position to challenge a provider when there is a problem. The situation is worse, however, in managed care, where the patient must contend not only with a physician but also with a formidable administrative organization. Id.

30. See, e.g., Kenneth J. Arrow, Uncertainty and the Welfare Economics of Medical Care, 53 AMER. ECON. REV. 941 (1963).

31. Herbert A. Simon, Models of MAN (1957); Herbert A. Simon, Models of Bounded Rationality (1982); Herbert A. Simon, A Behavioral Model of Rational Choice, 69 Q.J. ECON. 99 (1955); Herbert A. Simon, Rational Choice and the Structure of the Environment, 63 PSYCHOL. REV. 129 (1956).

32. Michael P. Keane \& Kenneth I. Wolpin, The Career Decisions of Young Men, 105 J. POL'Y ECON. 473 (1997).

33. See Frank A. Sloan et al., Parsing the SMoking PuZzle: Information, Risk PERCEPTION AND CHOICE (forthcoming 2003) (using data on persons over fifty years old to find 
rationality are tenable is both context- and individual-specific. In context, is it reasonable to assume that people can predict their own utility in a specific state of the world, that is, to know what they will like $?^{34}$ This plausibly depends on whether experience goods or credence goods are involved. For credence goods, this is unlikely even after the person has consumed the good. Also, people differ in their cognitive abilities to process information relevant for market choices and to obtain such pertinent information.

In the context of managed care, the question becomes how much people understand about their choices. That a person with a particular form of cancer demands the latest therapy is not at all surprising. Moral hazard, reflecting a reduced price at the point of service, would lead the patient to do this. The patient with health insurance is, for all practical purposes, fully insured for major expense and thus demands all improvements in care that yield as little as zero marginal benefit. And to the extent that the physician does not share in the marginal cost of such care, and in fact stands to profit from delivering additional services, he too may recommend such care, given the financial incentive he faces.

However, from an ex ante perspective, prior to a particular condition arising, an informed individual may realize that once an illness strikes he will want to consume care up to the level at which the marginal expected benefit from care is zero. Realizing this temptation, a forward-looking person may set up barriers to overuse in advance. This is much like precommitting to saving a given amount each month by specifying that cash be deposited into savings each month before one receives a paycheck. Or people may eschew buying peach ice cream, knowing that if the ice cream is in the home, it may be consumed before bedtime..$^{35}$

Such planning for future contingencies is a difficult task. Not only must the assessments be made ex ante, but future utilities must be assessed at various care levels for a particular condition. The problem is further complicated by the multiplicity of possible conditions.

Empirical evidence on consumer knowledge about provisions of their health plans is very limited, and hence the full extent of market failure due to imperfect consumer information is unknown. ${ }^{36}$ One recent study compared consumer

evidence that older smokers are forward-looking about their choices about quitting); Jonathan Gruber \& Botond Köszegi, Is Addiction "Rational”?: Theory and Evidence, 116 Q.J. ECON. 1261 (2001).

34. Daniel Kahneman, New Challenges to the Rationality Assumption, in CHOICES, VALUES, \& FrAMES 765, 765-67 (Daniel Kahneman \& Amos Tversky eds., 2000).

35. See Jon Elster, Alchemies Of The Mind: Rationality And Emotion (1999) (describing the concept of two selves in the same individual, where one self is rational and forwardlooking, while the other self is short-sighted and impulsive).

36. Korobkin argues that "the efficient outcome (from managed care) depends, like the predictions of most economic models, on the assumption that consumers are ruthless optimizers-that they carefully compared the detailed descriptions and fine print of health insurance plans, that they make complicated trade offs between price and services, and that they reward (with reenrollment) the MCO that tailors its offering to their preferences and punish (by selecting a competing plan) those that fail to do so." See Korobkin, supra note 15, at 45 . This statement can be analyzed on both a conceptual and an empirical level. Conceptually, no one would maintain that people are typically "ruthless optimizers." 
perceptions of their plans with the actual plan provisions. ${ }^{37}$ Consumers were generally knowledgeable about three of the four provisions studied; they overestimated the extent to which their plans restricted their access to specialists. If questions were asked about care patterns and levels for particular conditions, it is likely that consumers' perceptions would have been far less accurate. ${ }^{38}$

\section{B. Imperfect Risk Adjustment}

\section{Critique}

Under ideal circumstances, insurers would receive a premium commensurate with the actuarial value of expected losses. Because of differences in health and in tastes for medical care, consumers differ in the actuarial value of the loss in ways that cannot be perfectly observed by insurers. This produces the phenomenon known as adverse selection, in which those who seek insurance are at greater risk than the risk anticipated by the insurer. Insurers adopt various techniques for coping with adverse selection, including waiting periods and contracts designed to separate high from low users, ${ }^{39}$ but these methods are imperfect, and their use is limited by regulations that promote access to insurance by those at higher risk.

Even if there were no adverse selection in the initial choice of plan, suppose that a consumer develops an expensive chronic condition in a year. Given imperfect risk adjustment, the MCO will not want to retain the patient in the plan. Under perfect risk adjustment, premiums would rise to reflect the higher actuarial value of the loss after the person acquired the new condition. However, currently there is only limited use of risk-adjusted premiums and capitation rates to reward plans for providing care to sicker patients. ${ }^{40}$ Therefore, MCOs have an incentive to deliver lower quality care in the hope that sick patients will leave the plan. If patients are unable to appreciate gradations in

Nor is being ruthless in pursuit of self-interest a necessary condition for the market to lead to desirable outcomes. At an empirical level, Korobkin cites general articles from the psychological literature to argue for bounded rationality in the context of managed care. Id. at 48-51 (citing Herbert Simon, James March, John Payne, and coauthors James Bettman and Amos Tversky). More compelling evidence would come from choices people make about their health care in general and about choice of health insurance plan in particular. Such empirical evidence is currently lacking and merits a high priority for research.

37. Using data from the 1996 to 1997 Community Tracking Study, Cunningham and coauthors studied consumer information about plans by comparing consumers' responses on four study attributes of their health plan with information provided by the health plan. Peter J. Cunningham et al., Do Consumers Know How Their Health Plan Works?, HeAlth AFF., Mar./Apr. 2001, at 159, 160. The enrollees had fairly accurate perceptions of three of the four plan attributes; they tended to substantially overestimate restrictions on access to specialists, the fourth attribute. Id. at 161-62.

38. Even so, one can ask whether a fully informed consumer would have preferred a plan granting access to care up to the point of zero marginal benefit over one that limits access to care with marginal benefit less than marginal cost but with a lower premium. An interesting study would be to analyze the plan choices physicians would make when faced with this cost-quality trade-off.

39. Michael Rothschild \& Joseph E. Stiglitz, Equilibrium in Competitive Insurance Markets: An Essay on the Economics of Imperfect Information, 90 Q.J. ECON. 629 (1976); see also Cutler \& Zeckhauser, supra note 21, at 634-37.

40. Robert A. Berenson, Beyond Competition, HeAlth AFF., Mar./Apr. 1997, at 171. 
quality, MCOs may retain these patients, but at least they will save money. If patients recognize that they are receiving less care, they will leave, which saves the plan money in future periods. Thus, the inability to accurately measure health risk and fully reflect it in payments to insurers is a form of market failure that can give rise to consumer protection concerns. This is one reason why inadequate risk adjustment may be thought of as the Achilles heel of managed care and managed competition. ${ }^{41}$

\section{Counterpoint}

The most direct solution to inadequate risk adjustment is an improvement in the method of risk adjustment. ${ }^{42}$ If MCOs are paid for the increase in the actuarial value of coverage following the onset of a condition, they will have a lower incentive to avoid sick patients or to attract only healthy ones, a practice known as cream skimming. However, risk adjustment at present is far from an exact science. Thus, at least for now, it is necessary to rely on several second-best market and public policy alternatives for mitigating preferred risk selection of healthy persons by MCOs. Included among the market mechanisms is potential reputation loss when a plan excludes its sickest members, and pressures from tertiary care providers and specialists that may contract with MCOs to care for the sickest persons. Among the public regulatory mechanisms that precede the managed care patient protection movement are laws on guaranteed insurability and renewability of insurance. These laws prevent more overt forms of cream skimming, but in doing so they encourage subtler forms.

Given inadequate risk adjustment, MCOs have a disincentive to retain sick customers. Again, the issue of market failure hinges on information. In the

41. This is more of a problem in the context of managed care than in that of indemnity health insurance for two reasons. First, adverse selection is worse when people have a choice of health plans, since this gives them more opportunity to sort themselves into higher and lower risk groups (rather than simply declining insurance altogether). Under traditional insurance, which sets no limits, there was little need to offer a choice of plans; however, larger employers who offer HMOs usually offer a choice of plans. Second, managed care provides insurers many more opportunities to discourage higher risks than does traditional insurance.

42. Expenditures on personal health care services are subject to both large random variation as well as predictable variation among individuals. The latter gives rise to adverse selection by those demanding health insurance and preferred risk selection by insurers. One study concluded that overall, managed care plans have a twenty to thirty percent prior utilization advantage over conventional indemnity plans, which would reflect a combination of selection of favorable risks by MCOs and adverse selection of less healthy persons toward conventional health insurance plans rather than HMOs. Sherry Glied, Managed Care, in HANDBOOK, supra note 21, at 731.

To cope with these problems, the solution of which is a necessary condition for competitive health insurance markets to function in the public interest, researchers have developed various risk adjustment approaches. Risk adjustment accounts for variations among insureds in anticipated health care expenditures so as to permit development of more accurate premiums. For a comprehensive review of risk adjustment approaches, see Wynand P.M.M. van de Ven, Risk Adjustment in Competitive Health Plan Markets, in HANDBOOK, supra note 21, at 606, 757. For a discussion of risk adjustment in the context of Medicare, see Leslie M. Greenwald, Medicare Risk-Adjusted Capitation Payments: From Research to Implementation, HeAlth CARE FinAnCing ReV., Spring 2000, at 1, 2-3, as well as Lisa Iezzoni \& John Ayanian, Paying More Fairly for Medicare Capitated Care, 139 NEw ENG. J. MED. 1933 (1998). Rather than impose special data collection requirements, risk-adjustment methods typically are based on information routinely collected as part of the patient encounter, such as ICD-9-CM codes. 
short run, MCOs may employ techniques to encourage sick customers to disenroll. But, in the longer run, healthy persons will not want to join a plan that forces sick people out; they demand insurance because they face a nontrivial probability of becoming sick themselves. A response might be that dumping is difficult for outsiders to observe. But if it is difficult for a purchaser, such as an employer, to observe such practices, can one have confidence that a public regulator will have better access to such information? The answer to this question cannot be deduced; empirical evidence, currently lacking, is needed. Furthermore, given the subtleties of risk selection, public regulation without adequate risk adjustment is likely to require considerable government expenditures for monitoring.

\section{Myopic Orientation of Health Plans}

\section{Critique}

MCO decision-making sometimes seems overly oriented to achieving shortrun returns. Health maintenance organizations got their name because they were to maintain health, using preventive care as appropriate. ${ }^{43}$ If the relationship between an enrollee and the plan were long standing, a plan offering a combination of preventive care interventions that minimize personal health expenditures over a long time span would be able to capture the downstream savings. With high rates of enrollee turnover, however, any such savings will probably accrue to other plans.

Also, the quality of information systems may be adversely affected by member turnover. The data for the information system comes in part from patient encounters while enrolled in the plan. Turnover reduces the potential of plans to track patients and physicians with whom they contract, as well as the incentive of plans to do this. Some experts have expressed concern about the lack of health plan investment in information systems, which may be critical to plans' holding providers accountable for their services and for monitoring quality of care. ${ }^{44}$ Critics claim that lack of appropriate information systems works against the managed care industry's claim that it can manage care better than traditional insurers. ${ }^{45}$

For various reasons, including $\mathrm{MCO}$ exits and entry, as well as changing contractual relationships between MCOs and providers, enrollee turnover

43. See Robert H. Miller \& Harold S. Luft, Managed Care Plan Performance Since 1980: A Literature Analysis, 271 JAMA 1512 (1994) (comparing preventive care in managed care versus traditional indemnity plans). Preventive care in managed care is a little higher. Better coverage of preventive care, however, may be used by MCOs to attract a healthier than average enrollment. See Glied, supra note 42, at 712 .

44. Ctr. for Studying Health Sys. Change, Managed Care Woes: Industry Trends AND CONFLICTS 3 (1998), available at http://www.hschange.org/CONTENT/68/index.html (last visited Sept. 19, 2002).

45. See Rodwin, Backlash, supra note 29, at 1117. 
appears to be about twenty-five percent per year. ${ }^{46}$ Although forward-looking consumers may in principle demand contracts with MCOs offering costminimizing levels of prevention, at a minimum, turnover makes it more costly to carry out a coordinated plan of preventive care interventions.

\section{Counterpoint}

The threat that an unsatisfied consumer will switch to a competitor is an important form of market discipline under competition. In this sense, if there were less churning from switching plans, the plans would have less incentive to satisfy consumer wants than they do presently. Firm exit/entry also is integral to the proper functioning of a competitive market. Some recent MCO exits from the Medicare Choice Program may be attributable to inadequate payment. Raising such payment may reduce high rates of enrollee turnover or churning, but this too comes at a cost. Various forms of solvency regulation, a traditional role of state insurance departments, may provide one, albeit imperfect, safeguard by limiting entry of MCOs that have a relatively high probability of insolvency. Bars to MCO entry should in part reflect the transaction costs incurred by switching and the degradation in quality of services of MCOs, including possibly lack of preventive care, as they become insolvent.

Because some degree of turnover is essential in a healthy, competitive market, plans will not have perfect incentives to invest in long-term preventive care. Patient protection laws conceivably could attempt to correct for this imperfection. However, by raising plan outlays for care, patient protection laws might also worsen the problem by increasing costs or altering market conditions in a fashion that leads to more turnover. For instance, giving providers more bargaining clout may lead to more contract terminations, causing patients to switch plans in order to keep the same physician. It is still too early to determine whether the state laws have had these adverse effects.

D. Lack of Consumer Choice

\section{Critique}

Most private health insurance is purchased as group insurance through employers. This occurs for various market reasons (economies of scale in provision and avoidance of adverse selection by consumers) and public policy reasons (tax subsidy and ERISA preemption). ${ }^{47}$ Because group insurance requires a single contract for a large pool, however, it restricts the ability to vary contractual terms to fit individual tastes.

Moreover, employer-based coverage may introduce agency problems. ${ }^{48}$ An employer's preference does not necessarily reflect the preference of the

46. Mark A. Hall, Legal Rules and Industry Norms: The Impact of Laws Restricting Health Insurers' Use of Genetic Information, 40 JURIMETRICS 93, 109 (1999).

47. David A. Hyman \& Mark A. Hall, Two Cheers for Employment-Based Health Insurance, 2 YALE J. HEALTH POL'Y L. \& ETHICS 23, 25-29 (2002).

48. Id. at 27. 
workforce as a whole, much less the preference of any single employee, although there is a financial incentive for the employer to honor preferences of, at a minimum, the average employee. ${ }^{49}$

One mechanism for accounting for employee heterogeneity is to provide plan choice, but economies of scale limit the number of plans that any one employer can offer. Although this problem is not unique to managed care, managed care restricts choice of provider at the point of service, which may exacerbate the problem.

\section{Counterpoint}

Decoupling employment and acquisition of health insurance could increase consumer choice. However, this would also increase the administrative cost of insurance and increase adverse selection. To achieve economies of scale in the provision of health insurance, a second-best option may be to use purchasing pool arrangements that replicate options that consumers would have in a more atomistic market structure. Adverse selection problems would remain, nonetheless; and new purchasing arrangements would add additional complexities to the already labyrinthine set of state and federal insurance regulations, which might undermine already fragile existing market structures. ${ }^{50}$ Therefore, an argument exists for increasing the range of choices that consumers have within their health plans.

\section{E. Standardization of Care}

\section{Critique}

Optimal care is provided where the marginal benefit of such care equals marginal cost. This normative standard requires that costs and benefits be measured from a social perspective, that is, considering the cost borne by all parties, not just the patient, and also including external costs and benefits. Traditional fee-for-service insurance tends to over-provide care at a level where marginal cost exceeds marginal benefit. ${ }^{51}$ Using a combination of external incentives, physician selection, and information for physicians in the form of practice guidelines and utilization review, the promise of managed care is to allocate resources so that equality of marginal benefit and cost is achieved. For a variety of reasons, including those discussed in this subsection, the socially optimal allocation of resources may not be attained.

49. In interviews with insurance agents, one of us (Hall) heard that small employers often pick the managed care plan that has the owner's personal physician in the network.

50. Mark A. Hall et al., Health Marts, HIPCs, MEWAs, and AHPs: A Guide for the Perplexed, HEALTH AFF., Jan./Feb. 2001, at 142, 147-51.

51. Thomas G. McGuire, Physician Agency, in HANDBOOK, supra note 21, at 503-19. 


\section{Counterpoint}

A strength of the traditional professional model ${ }^{52}$ in which patients and physicians interact on a one-on-one basis, ostensibly making decisions on the basis of the patient's clinical condition and preferences, is full recognition of patient heterogeneity in both condition and preferences. Although practice guidelines used by MCOs and others presumably reflect average benefit for a specified set of patient characteristics and clinical circumstances, in the end they cannot fully reflect the unique circumstances of each individual patient. Thus, even if adherence to a particular guideline were to improve care on average, in following the guidelines, physicians may substantially miss the mark in particular cases-hence the association of "cookbook medicine" with practice guidelines. The loss from such errors should be weighed against the possible improvement in care from adherence to practice guidelines. Given the growth in network/independent practice plans ${ }^{53}$ individual physicians are likely to face heterogeneity in the guidelines themselves. Adhering to many guidelines is undoubtedly costly to the individual physician. The multiplicity of plans and contracts imposes substantial transaction costs at the level of the physician practice and impedes diffusion of cost-reducing technologies and strategies. ${ }^{54}$ Although use of guidelines may be improved by implementing information systems, there is, as noted above, likely to be underinvestment in such information systems in view of the high rate of exit/entry in this sector.

Provision of care by physicians in closed panel plans would make adherence to a particular set of practice guidelines much more feasible. Perhaps the widespread consumer interest in open panel arrangements for doctors reflects a reasoned judgment that the gain from adherence to guidelines is not worth the loss in freedom of choice of one's physician. If so, the current lack of adherence to guidelines is not problematic. On the other hand, one can take a less sanguine view of the consumer whereby the consumer does not know what he or she is missing. In this latter case, lack of adherence to guidelines is possibly a very serious market failure.

F. Conclusion: Do the Alleged Market Failures Justify Managed Care Patient Protection Laws?

Several potential sources of failure in the MCO market have been discussed in this section: consumer ignorance and asymmetric information; imperfect risk adjustment; myopic orientation of health plans; lack of consumer choice; and excessive standardization. Clearly, all was not well with managed care at the turn of the century. Some public concern is justified.

52. Mechanic, supra note 22, at 100; Rosemary A. Stevens, Public Roles for the Medical Profession in the United States: Beyond Theories of Decline and Fall, 79 MiLBANK Q. 327, 332-34 (2001).

53. Jon Gabel, Ten Ways HMOs Have Changed During the 1990s, HEALTH AFF., May/June 1997, at 134, 136; Marsha Gold, The Changing US Health Care System: Challenges for Responsible Public Policy, 77 MilbanK Q. 3, 11-14 (1999).

54. Harold S. Luft, Why are Physicians So Upset about Managed Care?, 24 J. HeALth Pol. PoL'Y \& L. 957, 965 (1999). 
Managed care's potential, at least as it exists currently, to deal with the ills of the U.S. health care system has been oversold. However, diagnosing managed care's deficiencies is much easier than designing public policies to deal effectively with the defects. Moreover, some of the defects may simply reflect the industry's immaturity and so may prove to be partially self-correcting. Hastily conceived cures to real problems may have worse long-run effects than the underlying disease.

Nevertheless, every state has responded in some fashion to perceived deficiencies in managed care. Much of the response has been very recent, precluding a detailed empirical evaluation of the performance of these laws. However, much can be learned by simply documenting what the states are doing-the subject of the next section.

III

\section{STATE PATIENT PROTECTION LAWS AND THEIR ENFORCEMENT}

\section{A. Methodology}

This section reports the results of a detailed examination of the pattern of state patient protection legislation and the level of enforcement by state agencies. Our analysis is based on several sources of information. Preliminary information about state enactments was collected from the National Conference of State Legislatures and the Blue Cross and Blue Shield Association of America ("Blue Cross"), each of which tracks state legislation relating to managed care and health insurance. These existing compilations, however, have several limitations, ${ }^{55}$ and, therefore, independent evaluation and supplementation was necessary. The actual text of each statute (through the end of 2001) was read, and state regulators in all fifty states and the District of Columbia were surveyed during the summer of 2001 to determine whether additional legal sources, such as regulations, had been overlooked. ${ }^{56}$ This information was used to develop a detailed coding of state statutes and regulations and their effective dates.

In addition, the 2001 survey of state regulators determined the level of regulatory enforcement. ${ }^{57} \quad$ Information from a similar survey on medical

55. Most personnel who conduct this tracking do not have law degrees, and Blue Cross is a trade association that collects this information for advocacy as well as research purposes. Also, only statutory enactments can be comprehensively tracked, so these compilations have only spotty coverage of regulations. Finally, these existing compilations do not provide as much detail about the law's content as is required for some research purposes, and they use different classification schemes that are not always consistent with the purpose or focus of other researchers.

56. For each major law, regulators were asked whether the law existed in statute or in regulations prior to or apart from specific statutory provisions. We did not compile information on regulations that merely implement a specific statutory enactment.

57. Surveys were mailed to three to five regulators responsible for regulating managed care health insurance in each state. These regulators were requested to consult with each other, and with other colleagues, as needed, in order to generate a single survey response. Responses were obtained from all states. In a few instances, more than one response was returned from a single state, in which case 
necessity and coverage determinations conducted by researchers at Stanford University was included. ${ }^{58}$ Survey data were supplemented with information about general regulatory resources and enforcement activities from the National Association of Insurance Commissioners. Additional data were obtained from various public sources such as the Urban Institute's New Federalism project.

B. State Enactments

\section{The Pattern of State Enactments}

The history of state enactments is presented in Table 1, and Table 2 presents more information about the content and pattern of these enactments. By the end of 2001, all but three states ${ }^{59}$ had some type of law described as a managed care "patient bill of rights" or "patient protection act." Eight states first adopted such laws in 1995 or 1996, five states did not have their first major enactments until 2000 and 2001, and the majority (thirty-five) enacted legislation between 1997 and 1999.

discrepancies were resolved by follow-up phone calls. Missing responses were filled in by follow-up calls and by supplemental research on agency web sites and in specialty publications.

58. Linda A. Bergthold \& Sara J. Singer, Problems in Medical Necessity Decision Making (2002 working draft) (on file with authors).

59. Alabama, Michigan, Utah, and Wyoming. 
TABLE 1:

State Managed CARE Patient Protection LAws

\begin{tabular}{|c|c|c|}
\hline & $\begin{array}{c}\text { Date of First } \\
\text { Comprehensive Law }\end{array}$ & $\begin{array}{l}\text { Number of } \\
\text { Laws }\end{array}$ \\
\hline Alabama & None & 8 \\
\hline Alaska & 1998 & 11 \\
\hline Arizona & 2000 & 8 \\
\hline Arkansas & 1997 & 9 \\
\hline California & 1995 & 13 \\
\hline Colorado & 1997 & 11 \\
\hline Connecticut & 1997 & 10 \\
\hline Delaware & 1997 & 10 \\
\hline Dist. Columbia & 1999 & 8 \\
\hline Florida & 1997 & 11 \\
\hline Georgia & 1996 & 13 \\
\hline Hawaii & 1998 & 5 \\
\hline Idaho & 1997 & 8 \\
\hline Illinois & 2000 & 13 \\
\hline Indiana & 1998 & 11 \\
\hline Iowa & 1999 & 7 \\
\hline Kansas & 1997 & 8 \\
\hline Kentucky & 2000 & 10 \\
\hline Louisiana & 1997 & 9 \\
\hline Maine & 1996 & 15 \\
\hline Maryland & 1996 & 14 \\
\hline Massachusetts & 2000 & 11 \\
\hline Michigan & 1997 & 7 \\
\hline Minnesota & 1998 & 14 \\
\hline Mississippi & 1995 & 6 \\
\hline Missouri & 1997 & 13 \\
\hline Montana & 1998 & 13 \\
\hline Nebraska & 1997 & 7 \\
\hline Nevada & 1997 & 7 \\
\hline New Hampshire & 1998 & 11 \\
\hline New Jersey & 1997 & 16 \\
\hline New Mexico & 1997 & 15 \\
\hline New York & 1997 & 12 \\
\hline North Carolina & 2001 & 15 \\
\hline North Dakota & 1999 & 8 \\
\hline
\end{tabular}


[Vol. 65: No. 4

\begin{tabular}{|c|c|c|}
\hline & $\begin{array}{c}\text { Date of First } \\
\text { Comprehensive Law }\end{array}$ & $\begin{array}{l}\text { Number of } \\
\text { Laws }\end{array}$ \\
\hline Ohio & 1997 & 11 \\
\hline Oklahoma & 1999 & 13 \\
\hline Oregon & 1995 & 11 \\
\hline Pennsylvania & 1998 & 10 \\
\hline Rhode Island & 1997 & 12 \\
\hline South Carolina & 1999 & 13 \\
\hline South Dakota & 1999 & 7 \\
\hline Tennessee & 1999 & 11 \\
\hline Texas & 1997 & 16 \\
\hline Utah & None & 10 \\
\hline Vermont & 1997 & 12 \\
\hline Virginia & 1996 & 15 \\
\hline Washington & 1996 & 10 \\
\hline West Virginia & 1998 & 10 \\
\hline Wisconsin & 1999 & 9 \\
\hline \multirow[t]{4}{*}{ Wyoming } & None & 3 \\
\hline & $\begin{array}{l}\text { None }=3 \text { states } \\
1995-96=8 \text { states } \\
1997=19 \text { states }\end{array}$ & Low $3 r d=7.3$ \\
\hline & $\begin{array}{l}1998=8 \text { states } \\
1999=8 \text { states }\end{array}$ & Med 3rd=10.7 \\
\hline & $2000-01=5$ states & High $3 \mathrm{rd}=13.8$ \\
\hline Federal Bills & & 14 \\
\hline
\end{tabular}


[Vol. 65: No. 4 
This compilation tracks seventeen separate provisions in this body of law, described in detail below. As of the end of 2001, no state had all seventeen and the leading federal bills had fourteen provisions. Over half the states (twentyseven) had at least eleven of these provisions (both the mean and median were eleven), and only eight states ${ }^{60}$ had fewer than eight provisions. Eight states had as many of these provisions (fourteen) as are in the leading federal bills. ${ }^{61}$

The most popular state laws were those prohibiting so-called "gag clauses" and requiring the use of a "prudent layperson" standard to determine coverage of emergency services. Both of these laws existed in nearly every state (fifty and forty-seven jurisdictions, respectively, out of fifty-one). In the view of commentators, these are among the least significant of the different forms of patient protection. ${ }^{6}$

The least frequent laws were those imposing tort liability on managed care plans (fourteen states) and funding ombudsmen to advise and assist patients in filing appeals (eighteen states). These are among the provisions most favored by consumer advocates, and states with these provisions have the strongest packages of laws overall. ${ }^{63}$ These contrasts lend credence to the claim that patient protection laws are, in large part, window dressing intended to assuage political pressure to take some visible action against managed care. This view is also reinforced by observing that several of the more common provisions exist primarily in a limited or weak version.

Despite these limitations, as of the end of 2001, several significant provisions existed in a large number of states. Most states (forty-two) required a process for independent, external review of insurers' coverage decisions and required that women be allowed to go to obstetricians or gynecologists without the approval of a gatekeeper. Roughly half the states:

(1) allowed patients with chronic conditions to receive care from specialists without a gatekeeper's approval each time;

(2) required HMOs to offer purchasers a point-of-service option;

(3) defined medical necessity in a manner that limits private parties' ability to set coverage standards by contract;

(4) limited the use of financial incentives that encourage physicians to contain costs;

(5) gave physicians procedural protections before they can be removed from an insurer's network; and

(6) prohibited insurers from seeking indemnification from physicians for the insurers' liability.

60. Hawaii, Iowa, Michigan, Mississippi, Nebraska, Nevada, South Dakota, and Wyoming.

61. Maryland, Maine, Minnesota, New Jersey, North Carolina, New Mexico, Texas, and Virginia.

62. See Joan H. Krause, The Brief Life of the Gag Clause: Why Anti-Gag Legislation Isn't Enough, 67 TENN. L. REV. 1 (1999). The prohibition of so-called "drive-through deliveries," which exists in forty-one states, also has been criticized as largely symbolic. David Hyman, Drive-Through Deliveries: Is "Consumer Protection" Just What the Doctor Ordered?, 78 N.C. L. REV. 5 (1999).

63. States with both of these laws have an average of fifteen provisions; states with one or both of these laws average twelve provisions; and states with neither law average nine provisions. See Table 2. 
These provisions are especially noteworthy from a market failure perspective and each will be discussed in greater detail, according to the groupings shown in Table 2.

2. Liability and Appeal Laws, and Preserving Physician Independence.

Liability provisions address two issues. ${ }^{64}$ Most are aimed at holding HMOs and MCOs responsible for errors in making insurance coverage decisions. These laws adopt principles similar to bad faith liability under other types of insurance by imposing personal injury and sometimes punitive damages on insurers for failing to adhere to a specified standard of care in deciding whether treatment is covered by the terms of the insurance policy. The second type of liability law is focused on medical treatment decisions rather than insurance coverage decisions. These laws hold HMOs responsible for negligence committed by their agents, including treating physicians, in delivering medical care ${ }^{65}$ and they prohibit HMOs from shifting this responsibility exclusively to physicians by barring indemnification clauses in managed care contracts with physicians.

These liability laws respond directly to the market failure that results from patients' inability to judge quality. ${ }^{66}$ The first type of law relates to the quality of the insurance function and the second type to the quality of medical care. ${ }^{67}$ When it is difficult for consumers to evaluate quality at the point of purchase, market pressures may be insufficient to create financial penalties for shirking. In theory, tort liability will encourage plans to provide care and to honor their promises up to the level at which the marginal cost of extra care equals the marginal benefit of harm avoided. ${ }^{68}$ Also, plans may be more likely to adopt information systems directed toward loss prevention. On the other hand, liability may cause some plans to exit, further limiting consumer choice and increasing the amount of enrollee turnover that now occurs.

The liability provisions addressing medical treatment share a second, more controversial market failure rationale. They respond to the concern that MCOs may compromise physicians' professional independence. Patients rely heavily on their physicians' advice in deciding what course of medical care, if any, to

64. For a more detailed description, see PATRICIA Butler, KAISER FAMILY Found., Key Characteristics of State MANAged CARE ORganization Liability LAWS (2001), at http://www.kff. org/content/2001/3155/MCOReport.pdf (last visited Sept. 23, 2002).

65. Usually this takes the form of declaring that MCOs are not immune from shared liability by virtue of the general prohibition of the corporate practice of medicine, which a few states have interpreted to mean that MCOs cannot be held responsible for medical treatment decisions. Because most states do not interpret the corporate practice doctrine this way, most states have no trouble holding MCOs responsible under ordinary tort and agency principles, often by extending precedents previously set for hospital liability. See Sharon M. Glenn, Comment, Tort Liability of Integrated Health Care Delivery Systems: Beyond Enterprise Liability, 29 WAKE FOREST L. REV. 305 (1994).

66. See supra Part IIA.

67. Naturally, in MCOs, there is substantial overlap between the two, since coverage is often determined by medical criteria ("medically necessary"), and treatment decisions are influenced by whether coverage is available.

68. See generally Richard A. POSNER, ECONOMIC ANAlysis OF LAW, Ch. 6 (4th ed. 1992). 
undertake. Patients assume that physicians will not compromise their best interests, but new and sometimes hidden features of managed care may weaken physicians' fidelity. Ideally, liability acts as a safeguard for this agency relationship. It might be thought that physician liability is sufficient to protect patients' interests with respect to the core quality of care, making MCO liability merely redundant. ${ }^{69}$ However, to the extent that MCOs influence physicians to consider interests that are inconsistent with patients' interests, an agency imperfection is introduced that MCO liability helps to correct. Similarly, other provisions more directly preserve physician independence and the fidelity of physician agency by limiting the use of distorting financial incentives, requiring that physicians be allowed to speak their mind to patients, and giving physicians procedural protections that limit health plans' ability to discipline physicians who stand up for patients' rights.

The Coase Theorem implies that mandatory liability would not be necessary if we could expect market negotiations to assign liability in the fashion that optimizes the parties' collective interests. ${ }^{70}$ In the managed care context, however, there are special reasons why this might not be the case (beyond the generic issues of imperfect contracts, asymmetric bargaining power, and transaction costs). First, employers negotiate the primary insurance contract, and they may not fully or accurately reflect employees' preferences about liability. Second, liability for medical decisions is affected by behind-the-scenes contracting between MCOs and physicians that employers and patients may lack either the knowledge or the ability to alter.

Even if imposing liability in this context is viewed as desirable, the fact that only a small number of states have imposed liability by statute does not necessarily indicate a regulatory failure. Most states recognize (or at least do not contradict) these principles in their common law judicial rulings. Therefore, all that is needed is to bar shifting of liability through indemnification clauses, which half the states do. The greatest difficulty, therefore, comes from the preemption of state common law remedies by the Employment Retirement Income Security Act ("ERISA"). Without federal legislation on liability, state enactments that simply codify or modify common law are partially futile gestures.

External review laws address these same issues and share the same justifications. Because the goal is to conduct external review prior to any harm occurring from denial of treatment, social and private costs may be reduced. Since external review is less threatening to insurers than liability, it is less likely

69. Patricia Danzon, Tort Liability: A Minefield for Managed Care?, 26 J. LEGAL STUD. 491, 50708, 512-19 (1997); see also Richard A. Epstein \& Alan O. Sykes, John M. Olin Program in Law \& Econ., The Assault on Managed Care: Vicarious Liability, Class Actions, and the Patient's Bill of Rights, Working Paper No. 112 (Dec. 2000), at http://www.law.uchicago.edu/Lawecon/WkngPprs_10125/112.RAE-AOS.Managed\%20Care\%20paper.pdf.

70. For an explanation of the Coase Theorem and a discussion of its importance to law, economics, and public policy, see David de Meza, Coase Theorem, ThE NeW PALGRAVE Dictionary of ECONOMICS \& THE LAW 270-82 (Peter Newman ed., 1998). 
to increase plan exit rates, which is a source of turnover that leads to a myopic view when plans make decisions about long-term investments in preventive care. $^{71}$

Additionally, external review addresses the problem of incomplete or "relational" contracting that arises from the inability to specify in concrete detail exactly what medical services are covered by insurance, a problem exacerbated by patient heterogeneity. This difficulty results in very broad insurance coverage terms (such as "medically necessary", "nonexperimental", and "noncustodial"), that give great discretion to the initial decision-makerthe insurer or utilization review entity. Since these decision-makers have a conflict of interest, unreviewable decisions are not likely to result in coverage that fully meets the ex ante expectations of the contracting parties (that is, the decision they would have reached at the time of bargaining had they been able to address and fully articulate the specific issue under dispute). ${ }^{72}$

External review helps to solve these contracting imperfections. However, there is good reason to question whether even the reviewers will apply the contractually determined standard of coverage. If given legislative permission, or even if not, reviewers may insist on care where the marginal benefit is zero, or nearly so.

As with liability, one can ask why the parties might not themselves require external review by contract, or why external review ought not be simply a default rule that parties opt out of by explicit contract. Responses to these possibilities are identical to those regarding the liability provisions-the transaction costs, information limitations, and agency imperfections that arise from the complex nature of this four-party contracting network (patient, provider, health plan, and employer). However, the concern may be greater here. There is a tendency in these laws (discussed more below) to specify not only a review process but also a substantive standard for coverage, by defining what medical necessity means or by requiring the use of a general medical necessity criterion. This foreclosure of contractual options requires additional justification and scrutiny.

\section{Provider-Access Laws}

Laws that enhance patients' access to physicians and providers exist in two general categories. Broader laws allow access to providers for any patient who might desire access or whenever such access might have medical justification. Narrower laws restrict these access rights to special categories of care or espe-

71. See supra Part IIC

72. Naturally, there is a significant risk that these decisions will be made from the ex post perspective of an ill patient who has already purchased insurance, which introduces a different type of conflict of interest (cost is no object for a patient who has no other options, even if the treatment has very low to no probability of working). See Mark A. Hall \& Gerard Anderson, Models of Rationing: Health Insurers' Assessment of Medical Necessity, 140 U. PA. L. REV. 1637, 1676-81 (1992). However, this bias is not greatly different from the hindsight bias that tends to affect liability decisions. Neither bias is a strong enough reason to avoid these protections altogether, but they strongly inform the proper procedural and substantive rules-a topic that exceeds the scope of this paper. 
cially compelling medical conditions. Some access laws fall mainly into the second grouping. "Any-willing-provider" ${ }^{73}$ and "freedom-of-choice" laws ${ }^{74}$ usually apply only to limited types of physicians or licensed professionals, and continuity-of-care provisions are often limited to patients with special conditions such as pregnancy, terminal illness, or especially severe disease. Other access provisions, however, such as "point-of-service" options ${ }^{75}$ and access to obstetrician-gynecologists apply more broadly.

The broader versions of these provisions have a weak relationship to market failure. The structure and content of managed care networks are among the core features of managed care and are primary considerations in selecting and negotiating managed care insurance. Restricting different types of networks limits market options and therefore constrains informed consumer choice. However, these laws respond to the concern that employer selection of insurance limits the choice that individual consumers have and may fail to reflect workers' collective preferences. For instance, one might imagine that single male business owners might not fully consider some women's desire to have a specialist as their primary care physician. Even in less obvious situations, heterogeneity of preference in the workforce precludes any single selection that satisfies all preferences.

The difficulty with this justification of broad access provisions is that it has no apparent boundaries. The logical extension is to prohibit most versions of managed care and insist only on nearly pure indemnity insurance-a world to which we cannot and should not return. A much less intrusive solution is to require that employers offer workers a greater choice of plans. Some choice of plans is offered by larger employers, and the largest firms offer a wide array of plans. Expanding choice of plans to small firm workers is a major objective of some recent congressional proposals. ${ }^{76}$

Access provisions that are more narrowly tailored to chronic or especially severe conditions address two different concerns: insurers' incentive to provide poor service to those with chronic illness, and healthy consumers' difficulty ex ante in knowing their own likely preferences were they to become ill in the future-in short, the problems of risk adjustment and myopia (or salience). "I knew having cancer was frightening, but I did not realize that it would be this terrifying." One response is "that's too bad. You made a bad choice. Better luck next time." However, the political response is more sympathetic, in part

73. These laws require insurers to include in their networks any provider (in the designated category) who is willing to meet the insurers' usual payment and contract terms. See Marsteller et al., supra note 2. We do not include here the version of these laws that applies only to pharmacies.

74. These laws bar an insurer from entirely avoiding one or more designated classes of providers, such as chiropractors, acupuncturists, or physician assistants. Id.

75. "Point-of-service" refers to a type of managed care plan that allows patients to seek care outside the provider network by paying a higher deductible and copayment. These laws require either insurers or employers to offer a point-of-service feature, so that purchasers or subscribers are not forced into a closed HMO system which does not offer any coverage outside its provider network.

76. See Hall et. al. , supra note 50, at 142-44. 
because of the potential that insurers will purposefully limit services for the highest cost illnesses.

Here, the laws appear to be a reasonably good fit with significant market failure concerns. They enact protections that more fully informed and prescient consumers might likely be willing to pay for and protections that are important in counteracting the risk selection problems created by regulations limiting insurers' ability to fully adjust rates to reflect the health risks of the chronically ill. Access to specialists accommodates changes in patient information and preferences following onset of illness and gives patients options to seek care from physicians who may have less incentive to skimp on care. However, this comes at a cost in terms of reduced ability of health plans to control their outlays and to direct patients into more effective forms of coordinated care.

\section{Mandated Coverage Terms}

Coverage laws also fall into two groupings. One type of law, known as a mandated benefit, requires coverage for a particular type of service under particular circumstances, such as an in-patient stay for a mastectomy. The other type of law specifies a general coverage standard by defining "medical necessity" or "emergency." Mandated benefit laws long preceded patient protection enactments or even managed care generally, and they are far too numerous to lend themselves to easy analysis. Some are justified by classic public goods considerations (for example, coverage of clinical trials), some by collective action or adverse selection concerns (for example, pregnancy), and some by predictable forms of consumer irrationality (for example, mental health). Others respond only to private interests of providers or advocacy groups (for example, coverage of chiropractic care).

There is no particular logic or pattern to the mandated benefits that are included as part of managed care patient protection laws, other than that they address the restrictions in coverage that have arisen most recently. The two examples we track here-maternity stays and mastectomies-each has a plausible justification in legitimate market failures. How strong the justification is merits further empirical inquiry. Even if these laws legitimately respond to a form of market failure, however, they still have the potential to cause other failures. Any mandate, by definition, will increase costs and will diminish choice. Therefore, mandates require careful individual evaluation, rather than across-the-board assessment, to determine how well they reflect collective consumer preferences, including willingness to pay for them.

A prudent layperson standard for emergency care likewise relates reasonably well to concerns about consumer myopia and public goods. The inability to think clearly and with foresight about health care needs, or to rationally deliberate over existing options, is especially acute for emergency conditions. However, the market justification is weak for specifying a uniform definition of medical necessity. First, this alters or constrains the fundamental terms of coverage that apply across nearly the full range of possible treatment situations. Second, there is no reason to believe that employers will not accurately repre- 
sent employees' interests in negotiating these terms, since owners and managers are covered by the same terms. Concerns based on heterogeneity of employees' preferences potentially apply with equal force to any provision of the insurance contract, but, as discussed above, there are less restrictive solutions than mandating contract terms that undermine a core purpose of managed care insurance-namely, to modify the professional standards that developed in response to inflationary, fee-for-service payment.

The strongest justification for laws defining medical necessity is that they are a necessary component in creating the external review mechanisms described above. Giving more definition to medical necessity could assist this review process if the contract completely fails to define the term, but this should be done only as a default provision that parties are free to alter, since the core purpose of external review should be to enforce the actual terms of the contract. If external review is to be mandatory, then legal provisions are required to prevent insurers from undermining this review mechanism by declaring, in effect, that medical necessity is determined solely by the insurer. Many medical necessity definitions, however, appear to go beyond this more limited role.

5. Disclosure and Information Requirements

Missing from this assessment is a discussion of laws that require health plans to collect and disclose market-enhancing information. Mandating improved information flow is usually the first step toward correcting market defects, since these measures usually have a low cost and thus are directly market-enhancing. Because disclosure requirements are relatively uncontroversial, and because they are amply discussed elsewhere,$^{77}$ they are not included in the main part of this study.

However, the following points are noted in passing. First, disclosure alone is unlikely to solve many of the more serious market defects, since these market failures are premised on consumers' inability to fully process the information they have. Simply focusing purchasers' decisions on possible future health states does not resolve the problem that people cannot accurately project changes in their preferences and values. Second, people have limits to the amount of information they can usefully process in a given transaction, so adding more information may actually worsen things by distracting people from what is most important to them. Finally, the disclosure requirements most common in patient protection laws primarily address the structuring and functioning of the health plan. They do not go to the essence of what consumers need to know in deciding on the purchase of credence goodsnamely, how well they will likely be cared for in the event of various kinds of illness.

77. See Mark A. Hall, The Theory and Practice of Disclosing HMO Physician Incentives, 65 LAW \& CONTEMP. PROBS. 207 (Autumn 2002); William Sage, Regulating Through Information: Disclosure Laws and American Health Care, 99 COLUM. L. REV. 1701 (1999). 


\section{Overall Assessment}

Patient protection laws have the potential to address a number of patient vulnerabilities created by the market defects identified in the first part of this article. Especially potent are liability and external review provisions, access to specialists for people with serious illness, and protecting physicians' independent judgment. Other provisions respond only weakly to legitimate market flaws, or appear likely to worsen the proper functioning of health insurance and health care markets. Most notable in this category are some benefit mandates, broad access guarantees, and prescriptions of coverage terms that constrain contractual flexibility and innovation.

Finally, certain forms of market failure are not addressed at all by patient protection laws. Nothing in these laws responds to health plans' lack of incentive, created by high turnover rates, to invest in the long-term health of their members. Furthermore, these protections deal only indirectly with the difficulties in anticipating and monitoring the core quality of care. Protections come primarily in the form of remedies for breach of obligation and expanded choice at the time of illness. However, these ex post protections are in tension with increased choice at the point of insurance purchase, which is the market's primary engine. Whether, on balance, they work to the advantage of consumers will depend in large measure on whether patient protections significantly increase costs and decrease the number of competitors.

\section{Regulatory Enforcement}

\section{The Need for Enforcement}

Legal enactments are only as good as the ability to enforce them. Therefore, one indication of whether patient protections laws are meant to address serious market problems, and how capable they are of doing so, is whether sufficient mechanisms and resources are in place for regulatory enforcement. Some patient protection provisions require no enforcement mechanisms. Other provisions require only minimal oversight, such as reviewing insurers' standard contract forms to determine that they contain required elements. However, other provisions can be expected to have differential impact according to the enforcement resources made available.

For instance, external review laws can be expected to have a greater impact if states provide assistance to patients in pursuing these appeals. Unlike liability claims, which have some prospect of attracting legal representation on a contingency fee basis, many patients will be unable or unwilling to pay for representation in appeals that pursue only the monetary value of treatment. Without representation, their appeal rights would not be as effective. Therefore, a number of states (eighteen) have created ombudsmen programs to assist consumers with pursuing these appeals. However, these laws exist in fewer than half the states with external review laws. 
Other provisions require additional monitoring and enforcement through regulatory agencies. Although patients or providers conceivably could sue for direct enforcement, only New Mexico explicitly creates a private right of action in its patient protection law. Moreover, patients are not likely to notice violations of some provisions, such as those affecting contractual relationships between plans and providers, and some violations are not likely to create stakes that merit legal action, even by providers. Therefore, insurers might conclude they can violate some provisions with impunity. For instance, most states require insurers to pay legitimate claims within a set time (so-called "prompt payment laws"), ${ }^{78}$ but the law attaches no penalty and most claims are too small, or delays too insignificant, to merit legal action. ${ }^{79}$ Therefore, several regulators have issued very large fines for insurers' repeated violations of these laws. ${ }^{80}$ This section explores the full extent of regulatory enforcement of patient protection laws.

\section{Description}

Managed care regulation occurs through three types of agencies. Most commonly (in thirty-nine states), the department that regulates other types of insurance has primary responsibility. In ten states, full or substantial authority is assigned to a division within the health department. Two states have special purpose agencies (the California Department of Managed Care and the Florida Agency for Health Care Administration). Among insurance departments, important distinctions include whether the commissioner is appointed or elected (eight states), and whether the department has a special division or office devoted to managed care regulation (nine states). Table 3 reports survey results on the following five types of enforcement activities conducted by these agencies.

78. Although these laws were enacted as part of the patient protection provisions, we do not include them in our study because they so clearly act as provider protections.

79. However, these violations might form the basis for a class action, as is being alleged in the class action suits against leading HMOs brought by physician organizations in several states. Tanya Albert, N.Y. Medical Society Sues Six Insurers, AMER. MED. News, Sept. 3, 2001, at 12; Molly Tschida, Taken To Task: Florida Docs Sue HMOs for Improper Claims Reimbursement, MODERN PHYSICIAN, Nov. 1, 1998 , at 10.

80. Cheryl Jackson, Georgia Makes Them Mind, AM. MED. NEws, June 18, 2001, at 19. 
[Vol. 65: No. 4 
(1) "Increased staff" indicates whether additional staff positions were created specifically to enforce state patient protection laws. Positive responses ranged from five to eight positions in eight states ${ }^{81}$ to one to three positions in thirteen states. Because there is not a high degree of confidence in the precise number of positions, this tabulation reports only whether some or no special positions have been created.

(2) "Directives" reports whether the agency has issued directives or bulletins notifying insurers of the requirements of patient protection laws. Most states have issued only one to two such communications ("few"), although nine states have issued three or more.

(3) "Investigations" reports whether states have conducted any investigations or audits to determine insurers' compliance with these laws. Market conduct examinations, audits, and special investigations were included as long as they focused on patient protection provisions as defined in this study, but routine follow-up or investigation of individual consumer complaints were excluded. Over half the states reported no such targeted investigations. The remainder reported anywhere from two to several dozen. A few states responded that every insurer is examined periodically for compliance with all laws, including patient protection laws. $^{82}$

(4) "Targeted fines" reports that twenty-three states had issued one or more fines or penalties against insurers for violations of these particular laws. Often, such fines were for violation of "prompt payment" laws, which require insurers to pay or respond to claims within a specified time limit. In several states, these are the largest fines in recent history against health insurers for any type of violation, amounting to several hundred thousand dollars per insurer, and over one million dollars overall. ${ }^{83}$ Although this study does not specifically address prompt payment laws, they were included as relevant for purposes of classifying fines since these laws were enacted in recent years as part of patient protection packages in many states.

(5) "General fines" reports the size of the state's highest fine issued against a health insurer in the past ten years for the violation of any insurance law, not just patient protection laws. This item is included based on interviews that indicate that, if the state has an established regulatory track record with respect to health insurers generally, that climate of

81. Arizona, Florida, Massachusetts, Maryland, Missouri, North Carolina, New Mexico, and Virginia.

82. We believe this may be true in several or many other states. Regulators may have been unsure about whether to report routine audits because of how our question was worded. Therefore, these numbers likely understate the amount of investigative activity as we attempted to define it.

83. See, e.g., 10 BNA HeALth L. REP. 1409 (2001) (\$1.4 million in fines against four Maryland plans); 10 BNA HEALTH L. REP. 1259 (2001) (Texas fines seventeen insurers a total of $\$ 9.25$ million); 10 BNA Health L. REP. 179 (2001) (\$1 million fine against Kaiser in New York); 9 BNA HeAlth L. REP. 1463 (2001) (Pennsylvania fines three HMOs a total of \$400,000). 
scrutiny is likely to carry over to new laws even if they have not yet been specifically enforced. Only sixteen states report fining a health insurer more than $\$ 100,000$ in the past ten years.

(6) "Enforcement count" reflects the number of categories in which the state has a positive response. "Enforcement weight" reports a total score based on whether the state's response was high or low, in those categories where responses were trifurcated. ${ }^{84}$ As can be seen, states' enforcement scores range widely, from the lower third averaging about one, to the upper third averaging over four out of the five categories of enforcement activity. This divergence is due to the fact that states in the extreme terciles tended to be either active or inactive in most categories, rather than activity patterns being scattered. ${ }^{85}$ Thus, for instance, states with newly created staff positions to enforce the law also were much more likely to have issued several bulletins and to have conducted targeted investigations or to have issued specific fines.

(7) The two columns relating to "ER violations" contain self-reported responses to two standardized questions, asking how likely it is that a violation would be detected, and what the most likely enforcement response would be, if "a health plan repeatedly was unreasonable in refusing to pay for emergency room care it thought was not a true emergency." Forty states were confident ("almost certain" or "very likely") they would detect this violation, and none thought it "unlikely." The probable response in most states (twenty-seven) was to issue a fine. The majority of the remainder who responded would order that the practice cease.

Differences in enforcement levels appear logically related to legal and market factors (Tables 4 and 5). As expected, enforcement increases according to the number of laws in each state and the length of time major enactments have been in place. Likewise, states with the fewest HMOs have the least enforcement, in part because these states also have fewer laws.

Also explored was the relationship of enforcement patterns to the structure of the agency and its enforcement resources and activities in other arenas. Overall, insurance departments have a higher score than do health departments (Table 4). ${ }^{86}$ Among insurance departments, scores are somewhat higher when the department has a division or office devoted to managed care, yet scores are

84. Weighting is done on a three-point scale (0 to 2), with 1.5 assigned to positive responses in categories with only two levels of response (none/some). In most of the following discussion, we use the weighted scores to reflect the level of enforcement activity.

85. All states with more than two directives and with targeted fines were in the top third in enforcement scores overall. All states except three with targeted investigations or with newly created staff positions were in the top half in overall scores. States in the lower half or third derived their enforcement scores primarily from issuing a few bulletins and/or from medium-sized general fines.

86. Enforcement did not differ in insurance departments with elected rather than appointed commissioners, even though elected commissioners have a reputation for being more consumeroriented. 
lowest among health departments, even though in all instances they also have a separate managed care division.

TABLE 4:

ENFORCEMENT SCORES BY AGENCY TYPE

\begin{tabular}{lccc}
\hline & $\begin{array}{c}\text { Ins. Dept. } \\
\text { Overall }\end{array}$ & $\begin{array}{c}\text { Managed Care } \\
\text { Division }\end{array}$ & $\begin{array}{c}\text { Health } \\
\text { Dept. }\end{array}$ \\
\hline $\begin{array}{l}\text { No. of Activities } \\
\begin{array}{l}\text { Mean Activity } \\
\text { Weight }\end{array}\end{array}$ & 2.8 & 3.0 & $\mathbf{2 . 2}$ \\
\hline
\end{tabular}

Bold indicates greater than $1 / 2$ point difference from adjacent number.

TABLE 5:

ENFORCEMENT SCORES BY TERCILES

\begin{tabular}{lccc}
\hline & $\begin{array}{c}\text { Low } \\
\text { States }\end{array}$ & $\begin{array}{c}\text { Medium } \\
\text { States }\end{array}$ & $\begin{array}{c}\text { High } \\
\text { States }\end{array}$ \\
\hline No. of Laws & 3.3 & 3.7 & $\mathbf{4 . 7}$ \\
Years In Effect* & $\mathbf{3 . 0}$ & & $\mathbf{4 . 8}$ \\
HMO Mkt. Share & $\mathbf{3 . 0}$ & 4.0 & $\mathbf{4 . 7}$ \\
Agency Budget** & $\mathbf{3 . 7}$ & 4.3 & 3.9 \\
General Examinations** & $\mathbf{2 . 7}$ & 4.1 & $\mathbf{5 . 0}$ \\
Agency Staff** & $\mathbf{4 . 5}$ & 3.5 & 3.7 \\
General Fines** & $\mathbf{4 . 4}$ & 3.7 & 3.7 \\
Chance of Detecting ER & & & \\
Violations* & 3.0 & 3.3 & $\mathbf{6 . 0}$ \\
Likely Response to ER & & & \\
Violations* & $\mathbf{3 . 3}$ & & 4.4 \\
\hline
\end{tabular}

Bold indicates greater than $1 / 2$ point difference from adjacent number. *Categories are used here rather than terciles. For Years In Effect, states are divided based on whether first laws were before (high) or after (low) Jan. 1, 1998. For Chance of Detecting and Likely Response, states are grouped using the responses shown in Table 3.

**Based only on states with primary enforcement through the insurance department

Managed care enforcement shows a curious pattern in relationship to general agency enforcement activities and resources. ${ }^{87}$ The expected pattern appears for per capita agency budget and for the number of examinations per insurer (Table 5). The lowest states in these measures also had less enforcement of managed care patient protection laws. However, the inverse

87. By general, we mean insurance generally, rather than health insurance or managed care. Therefore, this portion of the analysis pertains only to enforcement by insurance departments, which have jurisdiction over all types of insurance. 
relationship appears for agency staff and total fines, relative to the number of insurers in the state. For these measures, there is more patient protection enforcement in states with the lowest resources and activity overall, indicating that managed care enforcement may sometimes receive special or unique treatment or divert enforcement efforts from other areas.

\section{Evaluation}

From this survey, it is not possible to determine whether these enforcement activities are sufficient or excessive. That determination requires additional empirical investigation. However, it appears that states are not neglecting these laws and that the patterns of enforcement relate to legitimate differences in legal, market, and agency conditions. Also, it is noteworthy that enforcement levels are logically related to differences in states' self-reports about what would likely happen in response to a pattern of patient protection violations. States that reported a greater chance of detection and a stronger response had higher enforcement scores.

\section{IV}

\section{CONCLUSION}

This article concludes by reflecting on the broader themes of this symposium. Do the market defects identified explain why the managed care revolution has stalled? Can patient protection laws help put managed care back on track, or are they obstacles to meaningful reform?

From a perspective of reliance on market forces to achieve socially desirable outcomes, the fundamental failure of managed care is the failure to produce competing systems of health care delivery that force competitive processes and consumer choice to focus on trade-offs between the cost and the quality of care. The market has not generated integrated delivery systems that offer fundamentally different styles of practice and care management, analogous to the choice in transportation markets among bicycles, motorcycles, Neons, and BMWs. The market flaws identified share a large responsibility in this failure. If consumers cannot effectively identify and evaluate quality/cost trade-offs, then providers have little incentive to differentiate themselves on this spectrum, and they lack the information systems needed to determine which limitations in care are most cost-effective. Imperfect risk adjustment and high turnover make it more attractive for insurers to compete based on risk selection techniques than by improving the fundamental efficiency of care delivery. Additionally, employer-based purchasing shields the ultimate consumers of health care from the true costs, giving rise to chronic dissatisfaction with cost-containment initiatives.

Few of the patient protection laws address the fundamental sources of these market flaws. The exceptions are disclosure requirements, which attempt to improve consumer information, and some aspects of liability reform, which 
might help to move MCOs toward more truly integrated delivery systems. ${ }^{88}$ Most of these laws attempt to treat only some of the symptoms of market defects without curing the disease. In particular, these laws do nothing about the source of health plans' disincentives to invest in long-term health or to encourage enrollment by people with health problems.

No market functions perfectly, however, and the social and economic disruptions that would result from curing some of these market defects are not tolerable-for instance, eliminating employer-based insurance or allowing insurers to engage in unconstrained medical underwriting and risk rating. Therefore, these laws should not be blamed for failing to solve all of the market's problems.

Still, these laws can be faulted for their tendency to suppress the innovation and variation in medical care delivery that managed competition was meant to foster. Under one view of these laws, they are meant to enshrine a one-size-fitsall model of health insurance in which everyone enjoys a wide choice of providers, is subject to uniform standards of coverage and care, and is never bothered by cost-containment mechanisms. The "backlash" mentality would like to rid the country of HMOs, or force them back into a traditional indemnity mold. Recent market trends indicate a move in this direction, with distinctions among different types of insurance becoming increasingly obscure.

It is too early to conclude, however, that patient protection laws are responsible for these developments. This requires more in-depth empirical investigation. But judging from a surface inspection of these laws and their enforcement, it appears that they leave substantial room for the development and differentiation of managed care systems. The provisions that potentially are most threatening to the core attributes of managed care-_any-willing-provider" laws, uniform definitions of medical necessity, and restrictions on the use of financial incentives - are also the provisions that most often are enacted in a weakened or limited form.

The careful reader may be looking for a final assessment of the overall desirability of these laws. This article purposefully eschews any such ultimate pronouncement, but instead adopts a limited perspective, which describes the laws in the context of the more important market failures rather than assessing the "effectiveness" of such laws empirically. Not only would such an assessment be premature, but a prerequisite to assessing the effectiveness of a "reform" is obtaining a firm grip on what such reforms should accomplish. Further evaluation requires not only more empirical assessment, but also requires consideration of other perspectives such as political or social theory.

In the social movement that gave rise to patient protection laws, both market and political processes, and most likely an interaction between the two, are saying that core features of the first generation of managed care are unde-

88. See Clark C. Havighurst, The Backlash Against Managed Health Care: Hard Politics Make Bad Policy, 34 IND. L. REV. 395, 412-15 (2001); Clark C. Havighurst, Making Health Plans Accountable for the Quality of Care, 31 GA. L. REV. 587 (1997). 
sirable. By attempting to rehabilitate managed care, these laws create some hope that the revolution is not in fact "finished" in either sense of the term. On the other hand, some aspects of patient protection laws appear to respond primarily to lobbying by special interests, which would prefer to rid the world of managed care in all forms, and some aspects of the laws appear to have little practical significance. On balance, although the laws as enacted to date lack some important features that could address some of the shortcomings we identified in the first section of this article and address other concerns that seem to have less merit from a societal perspective, it is indeed possible that at least some of these laws are worthwhile. A judgment about this awaits a more indepth empirical assessment of the specific effects of these laws. 